\title{
IS AUDIO VISUAL METHOD BETTER THAN TRADITIONAL FOR MEDICAL STUDENTS? - A SURVEY REPORT
}

\author{
RUKHSANA PARVIN ${ }^{1}$, MD NAZMUL HAQUE ${ }^{2}$, NASER AHMED ${ }^{2}$, REZA AHMAD ${ }^{3}$, MD IMRAN ALI ${ }^{4}$, \\ ROWSAN ARA ${ }^{5}$, MUFTI MUNSURAR RAHMAN ${ }^{6}$, SWAPNA BHATTACHARJEE 6 , SHEKHAR \\ BHATTACHARJEE $^{6}$, AKM RAFIQUEUDDIN ${ }^{7}$
}

\begin{abstract}
s
Objectives: Different teaching aids are advocated in the medical colleges for delivery of lectures such as power point presentation, blackboard, transparency sheet, overhead projectors, extempore and lecture sheets. The aim of our study was to compare the more acceptable teaching methods between the students of Dhaka Medical College and Enam Medical College.

Materials and Methods: Total one hundred students were selected from fourth year in each medical college. They were asked to fill in a fourteen item questionnaire about their perception of five lecture delivery methods. Questionnaire was properly explained. The results were analyzed separately to find out any differences between preferences of teaching methods in both medical colleges.

Results: In DMC 50\% students preferred traditional blackboard method ,25\% PowerPoint presentations, 5\% both blackboard and PowerPoint, 16\% extempore and 4\% lecture sheet. On the other hand, in EMC, 53\% mentioned PowerPoint presentation as most acceptable, 38\% blackboard, 5\% combined blackboard and PowerPoint and 4\% extempore. Some important comments were recorded which could be valuable for the medical teachers.

Conclusion: The study showed that students of DMC clearly prefer traditional blackboard method rather than other teaching aids, whereas students of EMC prefer PowerPoint presentation. The study does not bring out any evidence based superiority of any lecture delivery method. It appears that any teaching aid can be appropriate and effective if the teachers are properly trained. This highlights the need for formal training in teaching technologies for good presentation and thus motivate the students.
\end{abstract}

Keywords: lecture delivery methods, blackboard, PowerPoint presentation, medical education

\section{Introduction}

Lectures can be traced as far back as the Greeks of the fifth century $\mathrm{BC}$, and in medieval times lectures were the most common form of teaching (Brown and Atkins, 1988) ${ }^{1}$. Therefore, the lecture has its merits. The most common method of teaching for medical students is lecture. Though small group learning is the best way for teaching, still we prefer lecture as we have a large numbers of students. Hence, it is immensely important that lecture should be as effective as possible ${ }^{2}$. A learner's learning style, whether visual, auditory or kinesthetic, is usually resistant to change ${ }^{3}$. Hence it is likely that mismatches exist between the learning styles of medical students and the teaching styles of medical teachers.

At present, the most common ways of lecture delivery include the lectures using PowerPoint (PPT) presentations, lectures utilizing the transparency and overhead projector (TOHP) besides the traditional 'chalk and talk' method. There is no conclusive study stating the superiority of one method over the other. Garg et al.(2004) have observed that students want the teachers to include audiovisual aids during the lectures, but it is not certain whether it increases

1. Assistant Professor of Medicine, Enam Medical College, Savar

2. Assistant Registrar, Medicine, Enam Medical College, Savar

3. Honorary Medical Officer, surgery, Dhaka Medical College and Hospital

4. Internee, Enam Medical College and Hospital, Savar

5. MD (Rheumatology) Final part student, BSMMU

6. Professor of Medicine, Enam Medical College, Savar

7. Professor and Head of the department of medicine, Enam Medical College, Savar

Bangladesh J Medicine 2010; $21: 60-67$ 
their understanding or performance in the examinations. Bartsch and Cobern (2003) noted that students preferred lectures with PPT over the use of TOHP, but that in some instances the content of the PPT presentation distracted students and they performed less well on tests compared with another group given lectures using chalkboard ${ }^{4}$. According to one study, traditional classes with blackboard presentation were the most favored by students from biomedicine and medicine courses ${ }^{9}$ while another study observed that most students preferred PPT presentations over traditional presentations (eg, chalk and talk). One extensive study comparing PowerPoint and TOHP observed no difference in student performance in tests (Szabo and Hasting, 2000) ${ }^{5}$ while in another study there was marked improvement in examination results when PPT replaced the use of TOHP (Lowry, 1999) ${ }^{6}$. Therefore, this study was undertaken to find out students' opinions of the impact of PowerPoint presentations in lectures compared with TOHP, lecture sheet, extempore and the traditional chalkboard teaching.

\section{Materials and Methods:}

A questionnaire-based survey of the medical undergraduate students in Dhaka medical college and Enam Medical College, Savar was conducted after getting permission from the principal and institutional ethical committee of the college. In these colleges, the annual intake of medical students is 175 and 100 respectively. A 14 item questionnaire was circulated to total of $2003^{\text {rd }}$ year medical students, 100 from each medical college. The students were asked to fill in the structured questionnaire about their views and perception regarding five methods of delivering lecture, i.e blackboard, PowerPoint, overhead projector, lecture sheet and extempore. They were also asked to write several comments regarding each method.

\section{Results:}

Perception of students from Dhaka Medical College:

The majority of medical students from DMC rated Blackboard teaching higher in terms of all the parameters studied as compared to the chalkboard or TOHP-based teaching. The students' preferences for each teaching aid (given as a percentage) were as follows:

$\S$ PPT: $25 \%$

$\S$ Blackboard: $50 \%$

§ TOHP: $0 \%$

$\S$ Lecture sheet:4\%

$\S$ Extempore: $16 \%$

\section{Perception of students from Enam Medical College:}

Majority students from EMCH preferred PowerPoint method. The students' preferences for a teaching aid (given as a percentage) were as follows:

- $\quad$ PPT: $53 \%$

- $\quad$ Blackboard: $36 \%$

- TOHP: 0\%

- Lecture sheet: 0\%

- Extempore :4\%

\section{In the opinion of the majority of students:}

1. With the blackboard method, there is more student-teacher interaction and less chance of attention diversion and the contents are easy to understand.

2. With the PowerPoint method, both text and images can be displayed on same slide, so it is clearly legible.

3. With the extempore method, teacher can make the whole subject interesting and easy for students.

4. With the lecture sheet method, It is helpful to follow lecture while teacher is delivering it.

\section{Comparison of preference: DMC versus EMC students:}

The medical students of EMC clearly preferred the use of PPT presentations. The blackboard method was the most preferred method among the DMC students $(50 \%)$ but this was not much appreciated by the EMC students (36\%). The DMC students showed more affinity towards the extempore method (16\%) as compared to their EMC medical colleagues (4\%). (figure - 1)

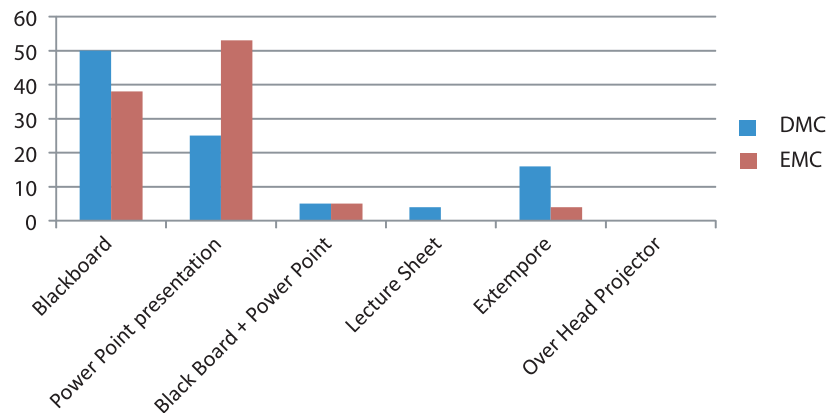

Fig.-1: Comparison of the preferences of DMC students with EMC students for each of the teaching method 


\section{Important comments provided by the medical students}

\section{Blackboard:}

1. The main reasons for being in favour of this technique were that the student-teacher interaction was better, maintenance of good eye contact, it helped taking down the notes and diagrams as the students follow the hands of the teacher and the lecture contained natural pauses and breaks.

2. The main reasons against this technique were that poor handwriting might not be legible and sometimes the blackboard was dirty. Also fewer diagrams were provided and less information was covered in the lecture.

Transparencies and overhead projector:

1. The main reasons for liking these techniques were that more information on the topic was covered in a shorter time

2. The main reason for disliking these technique was that any power failure interrupted the lecture, and sometimes the lecture delivery was too fast

3. Often if a large amount of information was presented in a single transparency it made the lecture monotonous and it was difficult to concentrate.

4. The issue of poor visibility and poor handwriting could be avoided by printing eg, by using PPT printouts and photocopying on the transparencies. The letter size should be clearly legible from a distance

\section{PowerPoint (PPT) presentation:}

1. The main reasons for liking this technique were that it provided a better quality of text and diagrams, and it avoided the issue of dirty blackboard and faulty chalks. PPT is more interesting because it can incorporate animations, pictures, graphs etc.

2. The main reasons for disliking this technique were that some teachers went too fast and then students found it difficult to cope up. Many students claimed that slides were not prepared by the teachers themselves in many occasion and that's why they could not read it properly and could not make it understandable to the students.

\section{Lecture sheet:}

Point in favour of lecture sheet was that it was easy to follow lecture when sheets were provided beforehand.

\section{Extempore:}

16\% DMC students and 4\% EMC students liked extempore (Figure -2).

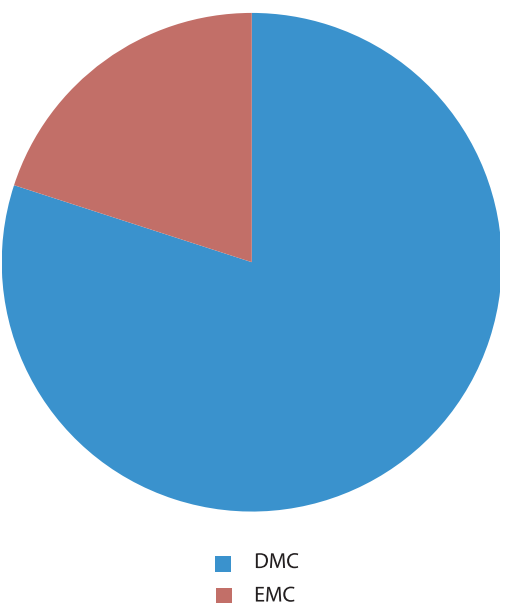

Fig.- 2: Pie chart showed DMC and EMC students' likings for extempore

They also commented that a teacher should be smart, should have clear voice and his pronunciations should be good.

\section{Discussion:}

From this study this was clear that there were differences in perception of lecture delivery methods between the students of DMC and EMC. Students from DMC favour in the order of priority blackboard $>$ PowerPoint $>$ extempore $>$ lecture sheet $>$ OHP whereas students of EMC have chosen Power Point> black board > lecture sheet and extempore > OHP. DMC students significantly preferred blackboard method than the EMC students.

\section{Possible reasons for difference:}

Though the syllabus and curriculum of medical students were same in both medical colleges, the preference of method was different, where teachers might be the main contributing factor. Regarding PowerPoint presentation $80 \%$ students of DMC stated that there were less student teacher interaction and eye contact was not properly maintained. More chance of attention diversion was there. Some teachers just read off the slides commented by $5 \%$ students. Some went through the slides so rapidly that it became difficult to follow for the students(10\%). Some prepared their slides with too much content that it seemed to be overloaded and boring. Few students noted out that the slides were not prepared by teachers 
themselves and as a result teachers feel uneasy to read slides during delivery of lecture. During class, $5 \%$ students kept themselves busy writing and thus they could not give attention to the materials. One disadvantage of PPT seemed to be that the student became a passive observer rather than an active participant ${ }^{13}$. It has been suggested that it is better to print out the PPT slides 20 and give them to the students, or put them online, and/ or to videotape the lecture and provide the videotape to the students.

But majority (53\%) of EMC preferred PowerPoint. $83.5 \%$ students thought that it was easy to understand and follow. According to $6.5 \%$, pictures, graphs and several images could be put altogether to make the topic interesting. $10 \%$ think that they were able to give more attention in this method. The students found presentations more interesting, as noted earlier, perhaps because of the novelty factor ${ }^{16}$. A study had pointed out that in PPT the ability to integrate text, pictures, and images was a great advantage which improved the educative value of the subjec $^{17}$. PPT was a program which could make a lecture very interesting ${ }^{21}$ or could cause distraction ${ }^{4}$, the difference was up to the teacher using $\mathrm{it}^{22}$.

Regarding blackboard method, $50 \%$ of the students of DMC liked this method.70\% of them thought that there was good student-teacher interaction. $5 \%$ stated that learning seemed to be more interesting. 5\% commented that there was less chance of attention diversion. Eye contact maintained be properly $(5 \%)$ and contents could be grasped nicely(5\%). Some students mentioned that in blackboard method teachers had their natural pauses, so it was easy to follow the lecture and cope up with the speed.

$38 \%$ students of EMC liked blackboard. Majority did not prefer it as they think that it was difficult to see from the distant (85\%) and hand writings was not legible(15\%). In this context, a chalkboard may be said to be more student-centered while PPT is more teacher-centered ${ }^{19}$.

In Overhead projector method, none of the students of DMC and EMC liked this. 80\% students thought that too much contents were placed on one page or slide, $10 \%$ think that sheets were poorly visible from distant, writings were not legible and faded(5\%) and transparencies were not properly placed sometimes(5\%). It was explained in an article that although the use of a TOHP was easy and had some advantages, at times it served as a distraction ${ }^{18}$.
4\% DMC students preferred lecture sheet method as they thought if the reading materials were provided before the class they could go through it properly and it was easy to follow teachers afterwards.

16\% DMC students and 4\% EMC students were in favour of extempore method where teachers deliver lecture without any aid. They liked it because they thought that a good teacher knew how to start at a basic point of the course and then lead them gradually through the new and more difficult points ${ }^{15}$.Smartness, clear voice, good pronunciation were expected from the teachers.

Some previous studies have found that students preferred $\mathrm{PPT}^{4,7,8}$ while in others the students preferred traditional blackboard teaching to TOHP and $\mathrm{PPT}^{9}$. One extensive study was suggested that the efficacy of PPT was case specific rather than universal ${ }^{7}$. Some had argued that PPT presentations encouraged an active learning environment, increased the effectiveness of lectures, and lend clarity to the subject $^{10-12}$. One disadvantage of PPT was that the student became a passive observer rather than an active participant ${ }^{13}$.It was suggested that although PPT had some positive effects, it did reduce the interactive discussion between teacher and students ${ }^{14}$.

\section{Conclusion}

In our survey report, there was difference of perception of methods of teaching was noted between students of DMC and EMC. But this study actually did not bring out any superiority of any method. It emphasizes that proper understanding of a lecture does not depend on the method but depends on the teacher. If the teacher is well trained, any method would be effective.T eaching is not the quality of technology, but the quality of teacher. Formal training in teaching technologies is needed to improve the presentation and thus motivate the students.

\section{Conflicts of interest: None}

\section{References:}

1. Brown G, Atkins M. Effective Teaching in Higher Education. London,UK: Routledge; 1988.

2. Walton AJ. Lectures, Tutorials and the Like. Oxford and Lancaster, UK:MTP; 1972.

3. Murray-Harvey R. Learning styles and approaches to learning: distinguishing between concepts and instruments. Br J Educ Psychol 1994; 64: 373-388.

4. Bartsch R.A.and Cobern K.M., (2003), Effectiveness of PowerPoint prese.ntations in lectures, Computers and Education, 41, 77-86. 
5. Szabo A, Hastings N. Using IT in the undergraduate classroom: should we replace the blackboard with PowerPoint? Comput Educ.2000; 35:175-187.

6. Lowry RB. Electronic presentation of lectures - effect upon student performance. U Chem Ed. 1999;8:1821.

7. Savoy A, Proctor RW, Salvendy G. Information retention from PowerPoint and traditional lectures. Comput Educ. 2009;52:858-867.

8. Rocklin T. PowerPoint is not evil. In: The National Teaching and Learning Forum. New York, NY: Greenwood Publishing Group; 1998.

9. Novelli ELB, Fernandes AAH. Students' preferred teaching techniques for biochemistry in biomedicine and medicine courses. Biochem Mol Biol Educ. $2007 ; 35: 263-266$

10. Hunt N. Enhancing lectures the modern way. The New Academic. 1998:3-9

11. Sammons MC. Using PowerPoint presentations in writing classes. The Technology Source. 1997. Available from: http://technologysource.org/article/ using_powerpoint_presentations_in_writing_classes. Accessed June 10, 210.

12. Rossen S, McGraw D, Graham E, Lee D. "Enhancing your lecture with presentation software-Setting instructional goals". 1997 Last updated September 1997 by David McGraw for Faculty New Media Center (FNMC) at UCLA Office of Instructional Development. Available from: http:// www.oid.ucla.edu Accessed June 10, 2010.

13. Casanova J, Casanova SL. Casanova SL. Computers as electronic blackboard: Remodeling the organic chemistry lecture. Educom Re. 1991:31-34.

14. Garg A, Rataboli PV, Muchandi K. Students' opinion on the prevailing teaching methods in pharmacology and changes recommended. Ind $\mathrm{J}$ Pharmacol. 2004;36:155-158.

15. Shallcross DE, Harrison TG. Lectures: electronic presentations versus chalk and talk - a chemist's view. Chem Educ Res Pract. 2007; 8:73-79.

16. James KE, Burke LA, Hutchins HM. Powerful or pointless? Faculty versus student perceptions of PowerPoint in business education. Business Communication Quarterly. 2006;69:374-396

17. Mayer RE, Anderson RB. The instructive animation: Helping students build connections between words and pictures in multimedia learning. J Educ Psych. 1992;84:444-452

18. Shah HK. Overhead Projector - A Versatile Teaching Tool. Indian J Community Med. 2006; 31. Available from: http://www.indmedica.com/journals.php?j ournalid? 7 andissueid? 73 andarticleid? 942 andaction?article. Accessed June 10, 2010.

19. Creed T. PowerPoint No! Cyberspace Yes! In: The National Teaching and Learning Forum. New York, NY: Greenwood Publishing Group. 1998.

20. Adkins J. PowerSpeak: Forgotten fundamentals of presentation speaking.2001. Available from: http:/ /lowendmac.com/lab/01/0712. html. Accessed June 10, 2010.

21. Ruffini MF. Creating Animations in PowerPoint to Support Student Learning and Engagement. EDUCAUSE Quarterly Magazine. 2009;32:4. Available from: http://www.educause.edu/ EDUCAUSE?Quarterly/ EDUCAUSE Quarterly MagazineVolum/CreatingAnimationsin Power Point/192966. Accessed June 10, 2010.

22. Harden RM. Death by PowerPoint-the need for a 'fidget index'. Med Teach. 2008;30:833-835. 